\section{ESPACIO CONTINUO}

REGISTRO TIPOLÓGICO DE LOS CARACOLES COMERCIALES DE SANTIAGO 1974 - 1983

Esta publicación -editada en pequeño formato y con una notable carga artesanal- es el resultado del catastro fotográfico realizado por Palma sobre un conjunto de caracoles comerciales en Santiago y que fue motivo de la exposición "Espacio continuo" realizada con apoyo de FonDART y presentada en Galería AFA a mediados de este año.

Los caracoles, símbolo del avance del comercio y el consumo en la década del ochenta en Chile, adelantaron de una extraña manera el advenimiento de otro tipo de centro comercial, el mall, hoy protagonista habitual en el panorama urbano nacional. Herederos bastardos de un orden que tiene un antecedente lejano en la escalera de Bramante en el Museo Vaticano y otro quizás más cercano en la sede neoyorquina del Museo Guggenheim de Frank Lloyd Wright, los caracoles santiaguinos hoy son testimonio de una gloria que duró poco y de la obsolescencia de un modelo inmobiliario equívoco, que intentaba multiplicar (y al mismo tiempo elevar) veredas $\mathrm{y}$ vitrinas.

Estos edificios, que en algún momento fueron ocupados por tiendas más elegantes y prósperas y que hoy alojan mayoritariamente peluquerías de barrio, talleres de reparaciones y pequeños cafés sin pretensión, aparecen en 34 imágenes insistentemente despobladas, tomadas a partir de 2008 por el autor. El ejercicio nostálgico del fotógrafo es acompañado por breves textos del curador Camilo Yáñez y el arquitecto Mario Marchant, profesor de la Universidad de Chile y responsable de una investigación tipológica sobre estos edificios comerciales que se detiene especialmente en los ejemplos construidos en la provincia chilena.

\section{Cristóbal Palma}

Ediciones Daga, Santiago

80 páginas, $14,5 \times 21 \mathrm{~cm}$, color

2012

Texto castellano, inglés

Web: www.edicionesdaga.com

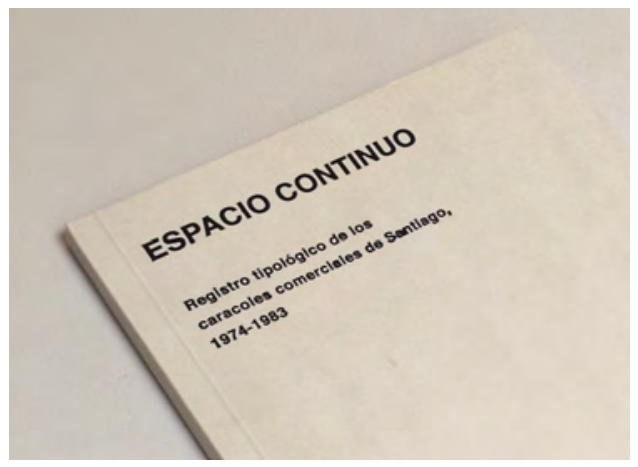

CANCHA

CHILEAN SOILSCAPES

En 2011 y por primera vez, el gobierno chileno -a través de la recientemente creada Área de Arquitectura del Consejo Nacional de la Cultura y las Artes- llamó a un concurso público para adjudicar la curatoría del pabellón de Chile en la Bienal de Arquitectura de Venecia. La celebrada iniciativa condujo a la selección, entre nueve propuestas presentadas, de "Cancha", el proyecto de Bernardo Valdés y Pilar Pinchart que planteaba la celebración del suelo como motivo arquitectónico, una reflexión en torno a la noción de campo y una apuesta por el territorio y las superficies vacías antes que por los objetos construidos.

Coincidente con el anuncio posterior de David Chipperfield respecto al tema de la xiır Bienal -"Common Ground"- el proyecto curatorial de "Cancha" suponía una estructura coral: convocó a siete colaboradores a aportar contenidos a la muestra. Germán del Sol, Pedro Alonso, Rodrigo Tisi, Iván Ivelic, Genaro Cuadros, ELEMENTAL y Juan Pablo Corvalán son los arquitectos chilenos que formaron parte del envío oficial y sus colaboraciones quedaron consignadas en este cuidado volumen -escrito únicamente en inglésque hace las veces de catálogo de la exposición. Quizás, el impreso sea el medio más idóneo para navegar por la intrincada red que, por ejemplo, van tejiendo las observaciones sobre el mercado del suelo presentadas por Cuadros, la selección de imágenes enviada por Del Sol y la reflexión de Tisi sobre la ocupación, la toma y la imposición aplicadas en la ciudad. Sin duda un proyecto ambicioso, "Cancha" encuentra en este catálogo la herramienta necesaria para desplegar en profundidad sus ideas.

María Pilar Pinchart, Bernardo Valdés (curadores) Consejo Nacional de la Cultura y las Artes, Chile 152 páginas, $20 \times 25 \mathrm{~cm}$, color 2012 Texto: inglés Web: www.canchachile.c

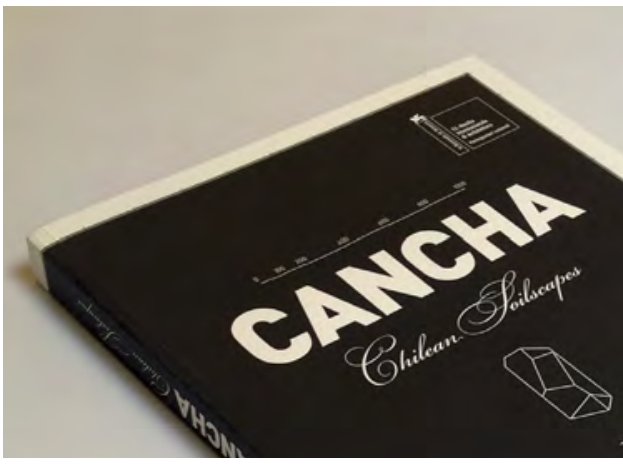

\section{URUGUAY/012 PANAVISION}

PRÁCTICAS DIVERSAS MIRADAS COMUNES

Iniciativa cruzada entre dos ministerios y la Facultad de Arquitectura de la Universidad de La República de Uruguay -que actuó como comisaria-, el envío de los orientales del Cono Sur a la XIII Bienal de Arquitectura de Venecia fue llamado "Panavisión" por sus curadores; este también es el título de la maciza publicación que da cuenta de él. A cargo de un arquitecto uruguayo $\mathrm{y}$ un chileno, quienes se apoyaron en una red que unía Montevideo, Buenos Aires, Santiago y Barcelona, la exposición enviada por Uruguay a Venecia se plantea como una "exhibición de prácticas" antes que de obras de arquitectura. A modo de un encargo de concurso, seis estudios emergentes fueron invitados a presentar, cada uno, una propuesta para la renovación del pabellón uruguayo en Venecia -no hay que olvidar que junto a Brasil y Venezuela, estos son los únicos países sudamericanos propietarios de un pabellón propio en la Bienal-. Siete restricciones orientaron el desarrollo de los proyectos, y la exposición presenta no solo resultados sino también etapas intermedias y todo el registro visible del proceso proyectual. Gualano y Gualano, 11:54 p.m., Fábrica de paisaje, MBAD, Bednarik y Mirabal y finalmente MAAM fueron las oficinas de arquitectura invitadas a participar en el proyecto "Panavisión". Además de las propuestas entregadas después de poco más de un mes de trabajo (informadas en el catálogo por medio de documentación planimétrica, croquis, modelos, visualizaciones y textos) extensas entrevistas a cada equipo de arquitectos, a cargo de los curadores Pedro Livni y Gonzalo Carrasco, ayudan a la entender el panorama de la arquitectura uruguaya reciente, fuertemente asentada sobre la tradición moderna.

Pedro Livni, Gonzalo Carrasco (editores)

Ministerio de Educación y Cultura, Ministerio de RR.EE. Universidad de La República, Uruguay 250 páginas, $22 \times 27 \mathrm{~cm}$, color 2012

Texto: castellano, inglés Web: www.farq.edu.uy

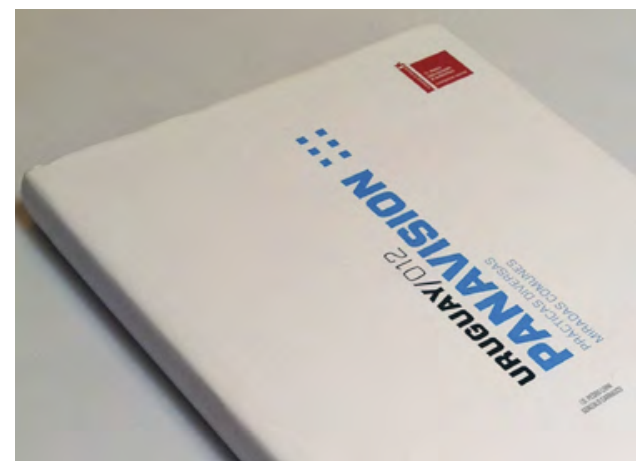


SUMMA+ $N^{\circ} 124$

ARQUETIPOS Y ABSTRACCIÓN

Unidad, superposiciones, desplazamientos, continuidades: así se anuncian en portada los contenidos del número de septiembre de la revista argentina summat. La inclinación creciente por prismas arquetípicos, las diversas exploraciones realizadas en torno a sus modos de asociación y la ausencia de articulaciones quedan registradas en la selección de proyectos publicados en esta edición, y articulan el ensayo con que Fernando Diez la presenta.

La procedencia de las obras parece confirmar ciertas afinidades intercontinentales: de las 16 obras publicadas, cuatro son chilenas -Pezo von Ellrichshausen, Cecilia Puga y una entrega doble de Eduardo Castillo- y tres son portuguesas -Aires Mateus, Nuno da Cerda Lopes, Souto de Moura-. Suiza, Inglaterra, Japón y Holanda aparecen también en el listado, además de otros casos de procedencia más híbrida, como la casa diseñada por el estudio brasileño-británico Procter $\&$ Rihl en Vermont).

Los cuerpos construidos sin juntas ni discontinuidades, en palabras del editor Fernando Diez, "invocan la solidez monolítica del obelisco, cuya unidad es tanto aparente como real... una unidad que depende fuertemente de las aristas, donde concurren dos superficies idénticas". Las obras que esta edición presenta tienen una deuda con Boullé y sus cenotafios: son construcciones que no hacen distingo material entre techos y muros, son edificios que evocan un cuerpo sólido y que intentan hacerse un espacio en la memoria de quien los habita. $\mathrm{O}$, probablemente $\mathrm{y}$ antes que eso, han salido de ella.

\section{INFRAESTRUCTURAS PROGRAMÁTICAS}

TALLER FAIDEN

La preocupación por la dimensión urbana del proyecto de arquitectura y una pregunta respecto a la capacidad del arquitecto -como agente propositivo y generador de programas- marcaron el derrotero del Taller de Proyecto Final de Carrera dirigido por el argentino Marcelo Faiden en la Escuela de Arquitectura de la Universidad de Palermo. Esta publicación, de modesta factura y cuidado diseño, documenta el recorrido del taller "Infraestructuras programáticas" y presenta, en primer lugar, una selección de proyectos de sus estudiantes, quienes trabajaron en una manzana completa del barrio porteño de Almagro para proponer la construcción de un complejo urbano de usos mixtos de entre 168.000 y $114.000 \mathrm{~m} 2$. Completos textos aportados por los invitados del taller, como Juan Herreros ("Geografía infraestructural”); Uriel Fogué, Eva Gil y Carlos Palacios ("Integrando la energía solar fotovoltaica") y finalmente Felipe Mesa ("Intereses de una línea”) ayudan a delinear el marco de acción del taller y a contextualizarlo. Tal como dice Juan Herreros, una de las aspiraciones deseables del arquitecto hoy es la descripción precisa del "funcionamiento de la Tierra"; ello supondría primero un entendimiento integrado de los diferentes sistemas que se superponen en el hábitat humano y, segundo, su integración al proyecto de arquitectura.

Es justamente la presencia de estos lúcidos textos la que amplía el interés y alcance de la publicación y al mismo tiempo plantea un interesante desafío para la difusión exitosa del trabajo de estudiantes y profesores.
Fernando Diez (director)

Donn S.A., Buenos Aires

Bimestral, septiembre de 2012

128 páginas, $24,5 \times 34 \mathrm{~cm}$, color

Texto castellano

Web: www.donnsa.com.ar

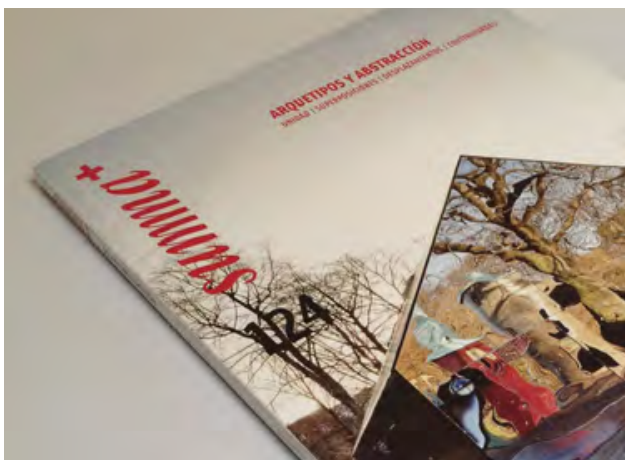

Marcelo Faiden (editor)

Nobuko, Universidad de Palermo, Buenos Aires

110 páginas, $21 \times 15 \mathrm{~cm}, \mathrm{~b} / \mathrm{n}$

2012

Texto castellano, inglés

Web: www.cp67.com

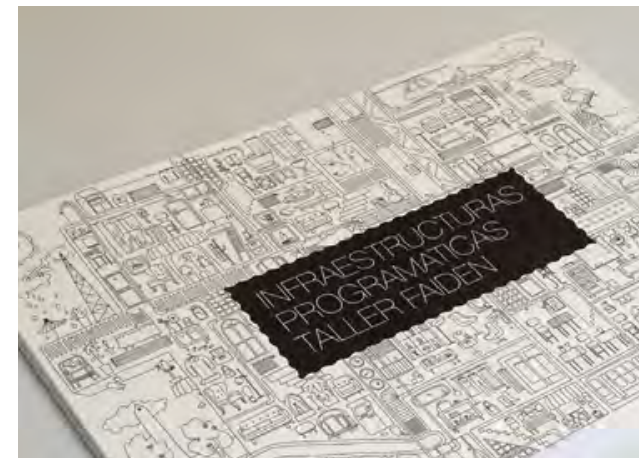

Esta es una de las últimas ediciones recibidas de la revista de la Escuela de Arquitectura de la Universidad del Bío Bío; se trata de un número dedicado al espacio público. Con una orientación decididamente académica, se presentan siete artículos que abordan el tema desde diferentes aristas, a veces con acentos más urbanos, otras con un punto más arquitectónico: las plazas de cinco ciudades de la Patagonia chilena -Puerto Cisnes, Puyuhuapi, Puerto Ibáñez, Bahía Murta, Punta Arenas-, el color en las calles de Valdivia, la autoconstrucción en Valparaíso y contribuciones provenientes desde las ciudades de Belo Horizonte y Montevideo.

Destaca la presentación de Pablo Fuentes y Elena Mayorga sobre un gran conjunto de vivienda obrera en Schwager, el colectivo Chollín. Un ejemplo notable de largos bloques residenciales, vinculados por un sistema de pasarelas y rampas, atribuido al arquitecto Ramón Acuña y construido como parte de las obras de reconstrucción en el área del Bío Bío tras el terremoto de 1939. Encargado por la Compañía Carbonífera y de Fundición Schwager, el conjunto y sus rasgos colectivistas son testimonio de una realidad social y cultural hoy en retirada, y de los enormes emprendimientos urbanos y de vivienda colectiva asociados a la industria minera del s. xx en Chile.
Hernán Ascui (editor)

Universidad del Bío Bío, Concepción

Mensual, diciembre de 2011

100 páginas, $20 \times 30 \mathrm{~cm}$, colo

Texto castellano, inglés

Web: arquitectura.ubiobio.cl

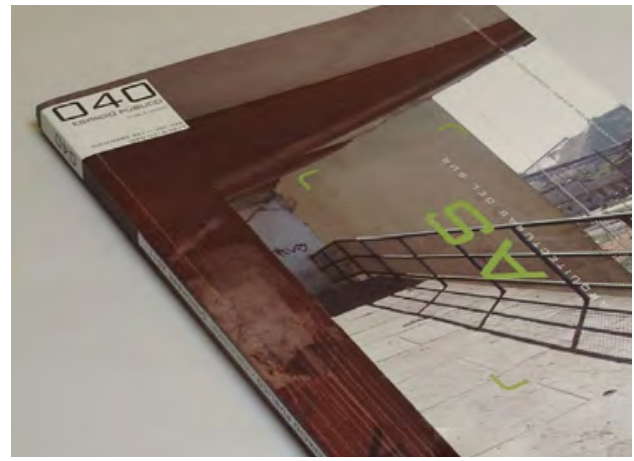

